Jurnal Konstruksi Hukum | ISSN: 2746-5055

Vol. 2, No. 2, Mei 2021, Hal. 396-400| Tersedia online di

https://www.ejournal.warmadewa.ac.id/index.php/jukonhum

DOI: https://doi.org/10.22225/jkh.2.2.3262.396-400

\title{
IMPLEMENTASI PEMIDANAAN TERHADAP PELAKU TINDAK PIDANA ILLEGAL LOGGING DI TAMAN NASIONAL WAY KAMBAS
}

\author{
Ida Ayu Naradita, I Made Minggu Widyantara, Ni Made Sukaryati Karma \\ Fakultas Hukum Universitas Warmadewa, Denpasar-Bali, Indonesia \\ dayunardit@gmail.com, Mademinggu21@gmail.com, Sukariati64@gmail.com
}

\begin{abstract}
Abstrak
Illegal Logging merupakan suatu rangkaian kegiatan yang saling terkait, mulai dari sumber kayu yang ilegal yang diperoleh dengan menebang pohon secara liar hingga sampai ke konsumen pemeroleh bahan baku kayu tersebut. Proses penebangan liar ini semakin nyata terjadi dan seringkali kayu hasil penebangan liar ini memasuki pasar-pasar yang legal dalam artian kayu-kayu ini sudah dilegalkan terlebih dahulu oleh para pihakpihak tertentu yang sudah bekerja sama dengan oknum aparat penegak hukum sehingga kayu-kayu tersebut mudah untuk memasuki pasar bahkan hingga sulit membedakan mana yang merupakan kayu illegal dan kayu legal. Penelitian ini bertujuan untuk mengetahui pengaturan hukum terkait pelaku tindak pidana illegal logging di Indonesia, dan untuk mengetahui hambatan dalam pemidanaan para pelaku tindak pidana illegal logging di Indonesia. Metode penelitian hukum normatif digunakan dalam pelaksanaan penelitian ini seta menggunakan pendekatan studi kepustakaan dalam mengkaji permasalahan yang telah dirumuskan. Hasil penelitian menunjukkan bahwa terjadinya sebuah tindakan melawan hukum tentu saja akan mendapatkan sanksi yang sepadan namun dengan proses yang semestinya. Dalam upaya pemberantasan kejahatan illegal logging, pemerintah menerapkan peraturan berupa Undang-Undang No.41 tahun 1999 tentang Kehutanan untuk menegakan hukum bagi para pelaku kejahatan illegal logging yang diharapkan mampu membuat jera para pelaku. Adapun hambatan dalam pemidanaan para pelaku, sudah terjadi saat proses penyidikan berlangsung. Hambatan-hambatan tersebut diantaranya, luas kawasan hutan tidak sebanding dengan jumlah personil tim gabungan dalam memeriksa hutan, sehingga ketika personil tim gabungan yang terdiri dari Polisi Kehutanan dan juga Kepolisian setempat melakukan pemeriksaan terkait laporan adanya kejahatan illegal logging, ketika sampai di tempat kejadian perkara, para pelaku sudah melarikan diri.
\end{abstract}

Kata kunci: Illegal Logging; Implementasi Sanksi; Tindak Pidana.

\begin{abstract}
Illegal Logging is a series of interrelated activities, from the source of illegal timber obtained by illegal cutting of trees to the consumers who obtain the wood raw material. This illegal logging process is increasingly happen and come true in Indonesian forestry, even sometimes the timber from illegal logging enters legal markets in the sense that this timber has been legalized in advance by certain parties who have collaborated with law enforcement officials so that the wood easy to enter the market and even difficult to distinguish between illegal timber and legal timber. This study aims to determine the legal regulation related to the perpetrators of illegal logging in Indonesia, and to find out the obstacles in the conviction of the perpetrators of illegal logging in Indonesia. The normative legal research method is used in conducting this research and this research also uses a literature study approach in examining the problems that have been formulated. The results of the research show that the occurrence of an action against the law will of course get a sanction that is commensurate with the due process. In an effort to eradicate illegal logging crimes, the government has implemented a regulation in the form of Law No.41 of 1999 concerning Forestry to enforce the law for the perpetrators of illegal logging crimes which are expected to deter the perpetrators. As for the obstacles in the criminalization of the perpetrators, it had occurred during the investigation process. These obstacles include, the area of the forest area is not proportional to the number of joint team personnel in examining the forest, so that when the joint team personnel consisting of the Forestry Police and the local Police conduct an investigation related to reports of illegal logging crimes, when they arrive at the crime scene, the perpetrators had already fled.
\end{abstract}

Keywords: Illegal Logging; Implementation of Sanctions; Criminal act.

\section{PENDAHULUAN}

Hutan merupakan amanah Tuhan Yang Maha Esa sebagai anugerah untuk bangsa Indonesia yang patut disyukuri. Wujud syukur atas karunia sumber daya alam berupa hutan tersebut dapat dilakukan dengan berbagai cara, seperti menjaga kelestarian hutan agar manfaat hutan tidak hanya dirasakan 
oleh generasi sekarang tetapi juga generasi yang akan datang (Redi, 2014). Dalam menjaga kelangsungan hidup manusia beserta makhluk-makhluk hidup lainnya, hutan memegang peranan penting. Oleh karena itu, hutan perlu dijaga kelestariannya agar tetap memberikan manfaat bagi kelangsungan makhluk hidup sehingga hutan harus dikelola, dilindungi serta dimanfaatkan secara berkesinambungan (Mustakim, 2013). Sebagai Negara yang kaya akan sumber daya alam, Indonesia memiliki banyak kawasan hutan yang tersebar luas di berbagai provinsi di Indonesia, hutan sendiri merupakan aset Negara yang bisa diperbarui dan dimanfaatkan guna meningkatkan taraf hidup masyarakat (Maddinsyah, Kustini, \& Syakhrial, 2018). Kawasan hutan Indonesia kurang lebih sekitar $70 \%$ (Tujuh Puluh Persen) dari luas daratan yang ada di Indonesia, hutan terbagi menjadi Rutan Lindung, Rutan Produksi , Rutan Konservasi dan sebagainya. Rutan banyak menyimpan sumber daya di dalamnya yang memiliki banyak potensi danjuga ekosistem, hutan juga berperan sebagai penghasil oksigen, tempat hidup flora dan fauna serta berperan sebagai pencegah timbulnya pemanasan global. Manfaat dalam hutan sendiri telah dijabarkan di dalam butir (a) Undang-undang No.41 Tahun 1999 tentang Kehutanan.

Pada hakikatnya, hutan berguna bagi kelangsungan hidup manusia. Hutan sebagai penyedia makanan bagi masyarakat sekitar hutan dan juga memelihara kesuburan tanah. Hutan yang ditumbuhi oleh pohon-pohon, binatang-binatang yang hidup di dalamnya memiliki keterkaitan satu sama lain sehingga harus dijaga kelestariannya (Salam, 2017). Sejak lahir, manusia sudah berada pada suatu ingkungan hidup sehingga lingkungan hidup merupakan bagian yang tidak dapat dipisahkan dengan manusia. Oleh karena itu, manusia seharusnya bisa lebih menjaga lingkungan hidup dan tidak merusaknya. Kejahatan terhadap lingkungan hidup seringkali dilakukan terutama pada hutan. Hutan yang kaya akan manfaat, rnenjadikan hutan seringkali dirusak oleh pihak-pihak yang ingin menguntungkan diri sendiri tanpa memikirkan akibat jangka panjang. Dengan luasnya hutan yang di mil iki oleh negara, tak jarang mengundang manusia untuk memanfaatkan hutan secara besar-besaran dan tidak sedikit yang sampai merusaknya. Salah satu kerusakan hutan yang sering terjadi yairu penebangan pohon secara besar-besaran tanpa memiliki izin dari perugas yang berwenang. Penebangan pohon secara liar ini dianggap memanfaatkan hutan secara besar-besaran tanpa memikirkan akibat jangka panjangnya. Penebangan liar sendiri memiliki arti rnenebang pohon dalam bentuk gelondongan yang tidak merniliki izin dari petugas yang berwenang. Penebangan liar atau yang sering disebut dengan illegal logging ini juga terhitung mulai dari penebangan pohon yang tidak sah, pengolahan kayu yang tidak sah, pengangkutan kayu dari hutan menuju pasar secara illegal, hingga menjual kayu secara ilegal.

Secara umum, penebangan liar atau illegal logging ini disebabkan oleh kepentingan ekonomi. Para oknum yang ingin mendapatkan untung yang lebih banyak, dan para buruh penebang pohonnya yang tidak lain adalah masyarakat sekitar hutan karena memang membutuhkan penghasilan untuk bertahan hidup sehingga masyarakat melakukan kejahatan illegal logging (Basuki, Mursyid, Kurnain, \& Suyanto, 2013; Budyatmojo, 2013). Dalam rangka perlindungan hutan, Pemerintah menetapkan sebuah peraturan yang mengatur tentang kehutanan yaitu Undang-Undang No.41 tahun 1999 tentang kehutanan. Pengendalian dampak lingkungan hidup merupakan suatu upaya dari pengawasan terhadap suatu aktivitas yang menimbulkan dampak besar terhadap kelestarian lingkungan. Pengaturan sanksi pidana yang diterapkan kepada setiap pelaku tindak pidana terhadap kehutanan khususnya illegal logging harus memberikan efek jera agar tidak mengulangi kesalahannya.

Berdasarkan uraian di atas, maka penelitian ini dirumuskan untuk mengetahui pengaturan hukum terkait pelaku tindak pidana illegal logging di Indonesia, dan untuk mengetahui hambatan dalam pemidanaan para pelaku tindak pidana illegal logging di Indonesia.

\section{METODE PENELITIAN}

Untuk mengumpulkan, mendapatkan, merumuskan dan menganalisis bahan hukum penelitian ini, penelitian ini memerlukan metode penelitian yang sistematis, terarah dan konsisten. Penelitian ini dilakukan dengan menggunakan metode penelitian empiris yaitu penelitian hukum yang terdiri terhadap identifikasi hukum (tidak tertulis) dan penelitian terhadap efektivitas hukum (Soekanto, 2007). Sumber data dalam penelitian ini yaitu sumber data primer dan sumberdata sekunder. Sumber data primer merupakan sumber data yang diperoleh langsung oleh peneliti dari sumber pertamanya, misalnya seperti hasil wawancara atau hasil pengisian kuesioner yang biasa dilakukan oleh peneliti (Umar, 2005). Pada pelaksanaan penelitian ini, peneliti melakukan wawancara kepada Kepala Polisi 
Kehutanan, Bapak Ida Bagus Nyoman Rai dan Kepala Humas Taman Nasional Way Kambas. Sedangkan sumber data sekunder merupakan sumber data yang dikumpulkan peneliti sebagai penunjang dari sumber data primer, data yang diperoleh berasal dari dokumen-dokumen danjurnal.

Teknik pengumpulan data yang peneliti gunakan yaitu dengan merode wawancara dengan mewawancarai informan yang berkaitan dengan masalah yang akan dibahas. Teknik wawancara yang digunakan adalah wawancara terstruktur. Wawancara merupakan suatu kegiatan pengumpulan data yang dilakukan dengan melalui percakapan dan tanya jawab yang dilakukan pengumpul data dan informan yang dirujukan unruk memperoleh data. Sedangkan wawancara strukrur adalah suaru proses wawancara yang dilakukan dengan pertanyaan-pertanyaan yang sudah tertulis kemudian diajukan kepada informan, runrunan pertanyaan-pertanyaan dan perumusannya sudah ditetapkan dan tidak boleh diubah-ubah.

\section{HASIL DAN PEMBAHASAN}

\section{Pengaturan Hukum Terkait Pelaku Tindak Pidana Illegal Logging di Indonesia}

Kerusakan hutan di Indonesia sudah sering terjadi, penyebab kerusakan hutan terbesar saat ini yaitu penebangan liar atau illegal logging. Penebangan liar atau illegal logging merupakan suatu kegiatan merusak hutan dengan cara melakukan penebangan, pengangkutan dan penjualan kayu secara tidak sah dan tidak rnemiliki izin dari pihak yang berwenang. Kegiatan illegal logging dilakukan terhadap hutan-hutan yang dilindungi ataupun dilarang. Kegiatan illegal logging juga terjadi ketika mengangkut kayu hasil penebangan liar, lalu termasuk proses ekspor dan memberikan informasi ke bea cukai, sampai sebelurn kayu dijual di pasar Legal (Sugianto, 2006). Indonesia memiliki banyak hutan yang dilindungi salah sarunya kawasan hutan Taman Nasional Way Kambas yang berada di Kabupaten Lampung Timur, Provinsi Lampung. Kawasan hutan Taman Nasional Way Kambas memiliki luas kurang lebih 130.000 hektare (ha) dan merniliki spektrurn ekosistem yang cukup luas. Di dalam kawasan dapat ditemui formasi-formasi hutan seperti hutan Mangrove, hutan Rawa dan hutan dataran rendah.

Dengan memiliki kawasan hutan yang cukup luas, membuat Hutan di Taman Nasional sering dijarah untuk diambil keuntungannya secara besar-besaran tanpa memikirkan akibat jangka panjang. Kerusakan yang terjadi diakibatkan oleh penebangan I iar atau illegal logging. Pelaku penebangan pohon secara liar biasanya adalah masyarakat sekitar hutan. Pengertian pelaku adalah seseorang yang dengan sengaja atau tidak sengaja dalam kondisi terdesak atau sudah ada niatan sebelumnya untuk melakukan tindak pidana. Dalam masyarakat sendiri, pelaku tindak pidana bisa siapa saja karena terjadinya suatu tindak pidana itu karena memang ada peluang yang membuat terbukanya celah untuk melakukan tindak pidana. Jika sudah terdoktrin dalam diri perbuatan melawan hukum dapat terjadi dan sebaliknya, jika tidak ada niatan dalam diri untuk melakukan tindak pidana maka tindak pidana tidak akan terjadi. Pemerintah dalam menghadapi tindak pidana illegal logging selalu mengupayakan dengan menjatuhkan sanksi yang sepadan dengan perbuatannya. Tindak pidana illegal logging adalah kejahatan terhadap hutan dengan cara menebang pohon secara liar tanpa izin dari pejabat yang berwenang sehingga mengakibatkan rusaknya hutan. Pada kasus illegal logging yang terjadi di kawasan hutan Taman Nasional Way Kambas, pihak polisi kehutanan setempat biasanya mendapatkan adanya laporan masyarakat mengenai kejahatan yang terjadi di suatu titik kawasan hutan, begitu menerima laporan, pihak polisi beserta tim gabungan diterjunkan ke lokasi kejadian dan ketika mendapati adanya kejahatan penebangan liar, pihak polisi kehutanan pun segera memeriksa para pelaku.

Dalam beberapa kasus yang didapati di hutan Taman Nasional Way Kambas, para pelaku biasanya tidak memiliki Surat lzin untuk memasuki wilayah hutan dan juga tidak memiliki Surat Angkut Kayu Olahan (SAKO). Barang bukti yang ditemukan berupa kayu hasil curian dan beberapa alat berat yang digunakan para pelaku yang kemudian disita oleh pihak yang berwenang. Hasil curian yang berupa kayu biasanya masih berbentuk gelondongan yang kemudian dirajang oleh tim polisi kehutanan menjadi kayu dengan ukuran panjang $40 \mathrm{~cm}-50 \mathrm{~cm}$, lalu kayu-kayu tersebut dibiarkan begitu saja menjadi humus. Kerusakan kawasan hutan telah menimbulkan dampak yang cukup luas dalam segala aspek, termasuk aspek lingkungan, aspek ekonomi, aspek kelembagaan dan juga aspek sosial-politik. Lemahnya pengendalian dan pengawasan terhadap operasionalisasi sistem perizinan dalam pengelolaan kawasan hutan dan alih fungsi kawasan menjadi perkebunan adalah salah satu penyebab terjadinya illegal logging yang berdampak pada kerusakan hutan (Iskandar, 2015). Oleh 
sebab itu, pemerintah mengatur sanksi pidana guna menjerat para pelaku kejahatan terhadap hutan. Sanksi pidana merupakan sebuah hukuman bagi seseorang yang mengalami kegagalan dalam mentaati hukum dan peraturan perundang-undangan, sanksi pidana mempunyai sifat memaksa dimana jika seseorang memang terbukti secara sah bersalah maka wajib dikenakan sanksi. Peraturan perundang-undangan yang mengatur sanksi pidana terhadap tindak pidana illegal logging yaitu Pasal 78 ayat (1) Undang-Undang No.41 tahun 1999 tentang Kehutanan.

\section{Hambatan dalam Pemidanaan Para Pelaku Tindak Pidana Illegal Logging di Indonesia}

Penerapan sanksi yang diterapkan kepada pelaku tindak pidana illegal logging diharapkan mampu membuat jera agar para pelaku tidak mengulangi perbuatannya. Dalam penerapan sanksi tindak pidana illegal logging, polisi kehutanan yang bertugas di Taman Nasional Way Kambas memiliki peran penting dalam memberantas tindak pidana illegal logging guna mencapai keberhasilan dalam penerapan sanksinya. Peran Polisi kehutanan yaitu melakukan patroli di kawasan hutan khususnya pada titik-titik rawan akan kejahatan, polisi kehutanan juga berperan dalam memeriksa kawasan hutan jika ada laporan dari masyarakat mengenai adanya kejahatan illegal logging di kawasan hutan, setelah menerima laporan, jika benar adanya tindak pidana illegal logging maka polisi kehutanan juga berhak untuk menangkap para pelaku. Namun, dalam melakukan pemberantasan, tak jarang petugas menemui hambatan, hambatan yang sering kali terjadi adalah saksi dan tersangka yang sering tidak hadir dalam proses pemeriksaan, tidak hadirnya saksi dan tersangka membuat proses pemeriksaan membutuhkan waktu yang cukup lama. Lalu, medan yang cukup berat ketika harus memasuki kawasan hutan, luas hutan tidak sebanding dengan jumlah person ii yang ada sehingga ketika personel melakukan pemeriksaan terkait laporan adanya tindak pidana illegal logging yang terjadi dan ketika sudah sampai ke tempat kejadian perkara, para pelaku sudah melarikan diri. Selain itu, keterbatasan dana yang dimiliki oleh petugas juga menghambat proses penanganan perkara karena tidak adanya dana untuk membawa alat berat ke lokasi kejadian guna mengeluarkan barang bukti dan alat bukti dari dalam lokasi hutan. Hambatan yang terjadi juga ada pada terbatasnya sarana dan prasarana yang dimiliki oleh petugas kehutanan. Namun, hambatan yang mudah terjadi yaitu adanya para oknum pejabat kehutanan yang sering terlibat dalam kejahatan illegal logging tersebut, sehingga pemberantasan illegal logging semakin sulit dilakukan. Para oknum pejabat kehutanan yang terlibat langsung dalam kejahatan illegal logging akan mendapatkan sanksi berupa penundaan kenaikan pangkat, penundaan pembayaran gaji hingga pemecatan, tergantung pada kasusnya.

Masalah penegakan hukum selalu berkaitan dengan hukum dan manusia sehingga sangat menarik untuk dikaji. Hukum tidak dapat diselesaikan sendiri dengan kehendak-kehendaknya karena hukum berupa kaidah. Oleh sebab itu, dibutuhkan adanya kehadiran aparat penegak hukum untuk mewujudkan kehendak hukum. Dengan cara memandang hukum seperti itu, maka penegakan hukum tidak sekedar menegakan mekanisme formal dari suatu aturan hukum, tetapi juga mengupayakan perwujudan nilai-nilai keutamaan yang terkandung di dalam kaidah hukum tersebut. Perlunya hutan untuk dilindungi, memang karena kondisi hutan yang sampai saat ini masih menghadapi beberapa persoalan kronis di kalangan pejabat kehutanan yang berkaitan dengan pengelolaan dan pengusahaan hutan.

\section{SIMPULAN DAN SARAN}

1. Simpulan

Berdasarkan hasil penelitian yang telah dijabarkan di atas, maka dapat disimpulkan bahwa pengaturan hukum terkait pelaku tindak pidana illegal logging di Indonesia harus dikenakan sanksi yang telah dijabarkan di dalam Pasal 78 ayat (1) UU No. 41 tahun 1999 tentang kehutanan; yang mana sesuai ketentuan hukum yang berlaku, para pelaku tindak pidana illegal logging akan dikenakan sanksi berupa pidana pokok maupun pidana tambahan yang penerapannya telah dilakukan di kawasan hutan Taman Nasional Way Kambas. Dalam penerapan sanksi pidana yang berlaku, ditujukan agar membuat para pelaku jera dan tidak mengulangi perbuatannya lagi. Adapun hambatan dalam pemidanaan para pelaku, sudah terjadi saat proses penyidikan berlangsung. Hambatan-hambatan tersebut diantaranya, luas kawasan hutan tidak sebanding dengan jumlah personil tim gabungan dalam memeriksa hutan, sehingga ketika personil tim gabungan yang terdiri dari Polisi Kehutanan dan juga Kepolisian setempat melakukan pemeriksaan terkait laporan adanya kejahatan illegal logging, ketika sampai di tempat kejadian perkara, para pelaku sudah melarikan diri. Hambatan selanjutnya yaitu 
sering kali beberapa oknum pejabat kehutanan, membantu para pelaku kejahatan illegal logging untuk melakukan aksinya menebang pohon, dengan begitu para pelaku bisa saja lolos dari pemeriksaan. Keterbatasan sarana dan prasarana juga menjadi hambatan selanjutnya. Pihak Dinas kehutanan seternpat tidak mempunyai alat berat yang mampu mengeluarkan barang bukti dan alat bukti dari dalam hutan sehingga itupun menghambat proses pemeriksaan terhadap pelaku. Namun, meskipun memiliki beberapa hambatan, pihak aparat kehutanan tidak menyerah dalam memberantas kejahatan illegal logging tersebut.

\section{Saran}

Berdasarkan simpulan di atas, hendak disampaikan beberapa saran ke berbagai pihak yakni dalam upaya penegakan hukum terhadap tindak pidana illegal logging yang merupakan tanggung jawab dari semua pihak, baik pemerintah maupun masyarakat, oleh karena itu dalam pelaksanaan pemberantasan illegal logging sangat diperlukan pemaksimalan kerjasama yang baik dari aparat penegak hukum dan juga masyarakat. Selain iru, pemerintah juga perlu melakukan sosialisasi kepada masyarakat tentang pentingnya menjaga kelestarian hutan agar rnasyarakat lebih mengetahui tentang pentingnya hutan dalam kelangsungan makhluk hidup di bumi. Kemudian, dengan dilakukannya sosialisasi atau penyuluhan sebagai upaya menanggulangi tindak pidana illegal logging, diharapkan masyarakat dapat ikut berpartisipasi dalam menjaga hutan dan mengerti mengenai semua aturan hukum tentang kehutanan sehingga dapat terjalin hubungan kerjasama antara pemerintah dan masyarakat dalam membantu kinerja aparat penegak hukum.

\section{DAFTAR PUSTAKA}

Basuki, K., Mursyid, A., Kurnain, A., \& Suyanto. (2013). Analisis Faktor Penyebab dan Strategi Pencegahan Pembalakan Liar (Illegal Logging) di Kabupaten Tabalong. EnviroScienteae, 9(1), $27-43$.

Budyatmojo, W. (2013). Penegakkan Hukum Tindak Pidana Illegal Loging (Antara Harapan Dan Kenyataan). Yustisia, 2(2), 91-100.

Iskandar. (2015). Hukum Kehutanan. Bandung: Mandar Maju.

Maddinsyah, A., Kustini, E., \& Syakhrial. (2018). Penyuluhan Manajemen Pemanfaatan Sumber Daya Alam Untuk Meningkatkan Perekonomian Keluarga Kampung Ciboleger Lebak - Banten. Jurnal Pengabdian Dharma Laksana, 1(1), 71-80.

Mustakim. (2013). Peran Polisi Hutan dan Masyarakat terhadap kelestarian Taman Nasional Alas Purwo di Resor Pancur, Kecamatan Tegaldlimo, Kabupaten Banyuwangi, Jawa Timur. AntroUnairDotNet, 2(1), 207-221.

Redi, A. (2014). Hukum Sumber Daya Alam dalam Sektor Kehutanan. Jakarta: Sinar Grafika.

Salam, R. (2017). Kearifan Lokal Masyarakat Adat dalam Pengelolaan Hutan di Pulau Wangi-Wangi. Walasuji, 8(1), 113-128.

Soekanto, S. (2007). Pengantar Penelitian Hukum. Jakarta: UI Press.

Sugianto, I. (2006). Manual Investigasi Illegal Logging: dengan pendekatan UU Kehutanan, UU Tindak Pidana Pencucian Uang, UU Pemberantasan Tindak Pidana Korupsi. Jakarta: Indonesia Center For Environmental Law.

Umar, H. (2005). Metode Penelitian Untuk Skripsi dan Tesis Bisnis. Jakarta: PT Raja Grafindo Persada. 